\title{
Temporal Genetic Differentiation of Cercospora beticola Populations in New York Table Beet Fields
}

Noel L. Knight, Niloofar Vaghefi, and Zachariah R. Hansen, Plant Pathology \& Plant-Microbe Biology Section, School of Integrative Plant Science, Cornell AgriTech at the New York State Agricultural Experiment Station, Cornell University, Geneva, NY 14456; Julie R. Kikkert, Cornell Cooperative Extension, Canandaigua, NY 14424; and Sarah J. Pethybridge, ${ }^{\dagger}$ Plant Pathology \& Plant-Microbe Biology Section, School of Integrative Plant Science, Cornell AgriTech at the New York State Agricultural Experiment Station, Cornell University, Geneva, NY 14456

\begin{abstract}
Annual epidemics of Cercospora leaf spot (CLS), caused by the fungus Cercospora beticola, can result in substantial defoliation in table beet fields in New York. High allelic and genotypic diversity have been described within $C$. beticola populations; however, information on the temporal stability of populations is lacking. C. beticola isolates were obtained from symptomatic leaves in three table beet fields in successive years. Two of the fields were organic mixed-cropping farms and the third was managed conventionally in a broad-acre cropping system. C. beticola isolates $(n=304)$ were genotyped using 12 microsatellite markers. Genotypic diversity (Simpson's complement index $=0.178$

to 0.990 ), allele frequencies, and indices of differentiation between years varied. Pairwise index of differentiation values ranged from 0.02 to 0.25 for clone-corrected data, and indicated significant genetic differentiation at Farm 2. No multilocus genotype was shared between years. The shift in multilocus genotypes between years questions the role of clonally reproducing primary inoculum. Collectively, these results suggest that a dominant inoculum source for initiating annual CLS epidemics is external to the field of interest. These findings have implications for CLS disease management in conventional and organic table beet production.
\end{abstract}

Cercospora leaf spot (CLS) of table beet (Beta vulgaris ssp. vulgaris L.), caused by Cercospora beticola Sacc., is a destructive foliar disease of table and sugar beet worldwide (Franc 2010; Lartey et al. 2010; McGrath et al. 2007). In the CLS-sugar beet pathosystem, the disease causes reductions in root weight and extractable sucrose (Franc 2010; Shane and Teng 1992; Smith and Martin 1978; Smith and Ruppel 1973). In broad-acre table beet fields, defoliation results in the inability to harvest by top-pulling machinery, which may result in complete crop loss. For fresh market table beet producers, the presence of foliar disease may lead to consumer rejection. In either system, the tolerance for foliar disease is low (Pethybridge et al. 2017b). New York is the second largest producer of table beets in the United States (USDA 2012), where production may be conventional or organic in broad-acre fields or small diversified farms. Broad-acre production of table beet may be for processing or value-added fresh market products. Production in small diversified farms is usually for fresh market sales direct to consumers (Pethybridge et al. 2017b).

Current address of N. Vaghefi: Centre for Crop Health, University of Southern Queensland, Toowoomba, QLD, Australia 4350.

Current address of Z. R. Hansen: Department of Entomology and Plant Pathology, The University of Tennessee, Knoxville, TN 37996.

${ }^{\dagger}$ Corresponding author: S. J. Pethybridge; E-mail: sjp277@ cornell.edu

Funding: This research was supported by the United States Department of Agriculture National Institute of Food and Agriculture Hatch project NYG625424, and the Federal Capacity Funds Initiative managed by the New York State Agricultural Experiment Station, Cornell University, New York.

*The $\boldsymbol{e}$-Xtra logo stands for "electronic extra" and indicates that one supplementary table is published online.

Accepted for publication 24 March 2018.

C 2018 The American Phytopathological Society
Management recommendations for CLS in table beet are an integrated combination of strategic and tactical practices. The potential to select table beet cultivars that are less susceptible or resistant to CLS is minimal considering that most commercially acceptable cultivars are susceptible or highly susceptible (Pethybridge et al. 2017a). Rotations of at least three years between susceptible crops (i.e., table beet, sugar beet, spinach, mangel-wurzel, and Swiss chard [McKay and Pool 1918; Vestal 1933]) are recommended (Koenick et al. 2017). These guidelines minimize the potential for epidemics to result from local sources originating within the field of interest. Local sources include colonized plant debris and alternative hosts (McKay and Pool 1918; Pool and McKay 1916). To promote degradation of colonized plant debris, burying by plowing or other forms of soil inversion is recommended after harvest (Jacobsen and Franc 2009; Khan et al. 2008). Control of potential alternative hosts is also recommended, as these have been considered green bridges for inoculum between seasons (Jacobsen and Franc 2009; Lartey et al. 2005). However, recent evidence has brought into question the role of the weed lambsquarters (Chenopodium album) as a significant source of inoculum. Cercospora spp. isolated from CLS lesions found on these plants in a table beet field in New York were identified as $C$. chenopodii (Vaghefi et al. 2017c). Thus, alternative hosts need careful investigation to better understand their role in contributing to CLS epidemics in table beet.

Despite the broad adoption of these management strategies, the high risk of crop loss from CLS epidemics and the polycyclic nature of the epidemics means that fungicides are the dominant control tactic used to reduce the rate of CLS progress (Pethybridge et al. 2017b). In conventional production, the durability of this approach is threatened by the rapid appearance and dominance of resistance to single site mode of action fungicides within $C$. beticola populations. For example, resistance to azoxystrobin in $C$. beticola populations from broad-acre conventional table beet production systems has been documented following field level control failures in New York (Abawi et al. 2014; Vaghefi et al. 2016). Resistance to major classes of fungicides also threatens the sustainability of CLS management in sugar beet. For example, resistance within $C$. beticola populations from sugar beet has been reported for benzimidazoles (Bugbee 
1996; Dovas et al. 1976; Georgopoulos and Dovas 1973; Ruppel and Scott 1974; Weiland and Halloin 2001), demethylation inhibitors (Bolton et al. 2012a, b; Karaoglanidis et al. 2000, 2001, 2002), and triphenyl tin hydroxide (Bugbee 1996; Giannopolitis 1978; Giannopolitis and Chrysayi-Tokousbalides 1980). The high risk of developing fungicide resistance within $C$. beticola populations is a direct function of the broad genotypic and genetic diversity and the potential for recombination (Bolton et al. 2012c; Groenewald et al. 2007, 2008; Moretti et al. 2006; Vaghefi et al. 2016, 2017a, b, c; Weiland et al. 2001).

No teleomorph has been identified for $C$. beticola, but two mating types have been reported (Groenewald et al. 2006). Mating type frequencies vary between $C$. beticola populations (Bakhshi et al. 2011; Bolton et al. 2012c; Groenewald et al. 2006; Obuya et al. 2011; Vaghefi et al. 2017c). When both mating types are observed in a near 1:1 ratio within a population, the presence of an active sexual cycle is suggested. In contrast, skewed mating type ratios may be reflective of a more clonal population (Milgroom 1996). C. beticola populations from table beet fields in New York have exhibited equilibrium and disequilibrium of mating type ratios, while microsatellite loci were in disequilibrium in each population (Vaghefi et al. 2016, 2017c).

C. beticola populations from around the world have been characterized using random amplified polymorphic DNA, amplified fragment length polymorphisms, minisatellites, microsatellites, and single nucleotide polymorphisms (Groenewald et al. 2007; Moretti et al. 2004, 2006; Turgay et al. 2010; Vaghefi et al. 2016, 2017c). These studies have unanimously reported high genotypic diversity, which has been interpreted as further evidence for sexual recombination events (Vaghefi et al. 2017c), although migration, mutation, asexual recombination (nuclear exchange, cytoplasmic exchange, or parasexuality), or mitotic recombination may also be involved (Burdon 1993; Burdon and Silk 1997; Milgroom 1996).

The genetic structure of $C$. beticola populations on table beet in New York was used by Vaghefi et al. (2017c) to test hypotheses regarding major sources of inoculum contributing to CLS epidemics. Genetic homogeneity and low differentiation of $C$. beticola populations among broad-acre fields suggested high levels of gene flow, and thus a potential impact of external inoculum sources. In contrast, high genetic differentiation of $C$. beticola populations between the mixed-cropping farms indicated limited inoculum dispersal between these fields, and was interpreted as evidence that local inoculum sources may play a major role in initiating the annual CLS epidemics in these farms (Vaghefi et al. 2017c). This is also congruent with previous reports that $C$. beticola has the potential to survive as pseudostromata on plant debris for 10 to 22 months (Khan et al. 2008). However, this survival estimate is based on studies conducted in North Dakota, and longevity of C. beticola in New York table beet fields is not yet known.

The primary objective of this study was to characterize temporal changes in genetic diversity and differentiation of $C$. beticola populations in table beet fields in New York. Knowledge of these changes, and survival of multilocus genotypes over time, is necessary for the development of hypotheses regarding the relative importance of local and external inoculum sources for initiating CLS epidemics and will inform management recommendations.

\section{Materials and Methods}

C. beticola sampling and isolation. Populations of $C$. beticola were collected from CLS lesions on table beet leaves from three table beet fields in New York from late August to early September in each year (Table 1; Fig. 1). Naming of sampling locations followed the convention presented in Vaghefi et al. (2016, 2017c), which used populations from the same locations. Sampling was conducted from a single conventional broad-acre $\left(>0.2 \mathrm{~km}^{2}\right)$ table beet field at Batavia in 2014 and 2016 (Field 2). This field was planted to cv. Ruby Queen (seed sourced from Seneca Foods, Dayton, WA) in both collection years, and rotated with soybean in 2015. The remaining fields were organic mixed-cropping farms in Hector and Phelps (Farms 1 and 2, respectively), and were sampled in 2015 and 2016. The mixed-cropping farms consisted of small-scale vegetable production with plots comprised of three to four $10 \mathrm{~m}$ rows of either table beet, Swiss chard, or other vegetables planted on an annual basis in close proximity. Farm 1 has been producing its own seed (cv. Detroit) since 2013 (seed sourced from Fedco Seeds, Clinton, ME), with this seed planted in both sampling years from the previous year's crop. Farm 2 used seed (cv. Detroit, Touchstone Gold, and Chioggia Guardsmark) from two different commercial suppliers each year (High Mowing Organic Seeds, Wolcott, VT; and Johnny's Selected Seeds, Fairfield, ME).

In each field, diseased leaves were collected following a hierarchical sampling protocol. C. beticola populations from 2014 and 2015 were collected in previous studies as described by Vaghefi et al. (2016) and Vaghefi et al. (2017c), respectively. In 2016, C. beticola populations were collected as described by Vaghefi et al. (2017c). Briefly, sampling occurred at defined intervals along arbitrarily placed transects at each location. Due to differences in cropping area, the number of leaves and the distance between sampling points varied between the mixed-cropping locations (Farms 1 and 2) and the broad-acre field (Field 2). In Field 2, diseased leaves were sampled from each of five locations at $20 \mathrm{~m}$ intervals along two transects. Ten diseased leaves were collected from individual plants within a $5 \mathrm{~m}$ radius at each sampling location. Farm 1 and Farm 2 each contained three to four contiguous rows of table beet, with each row sampled at 5 to $10 \mathrm{~m}$ intervals.

On each occasion, diseased leaves were stored in plastic bags at $4^{\circ} \mathrm{C}$ for $24 \mathrm{~h}$ before isolation. Lesions with conidia were covered with $50 \mu \mathrm{l}$ of T-water (Bolton et al. 2012c) and gently abraded with the pipette tip to dislodge conidia. The conidial suspension was spread across 2\% (w/v) water agar (Hardy Diagnostics, Santa Maria, CA) $(+0.02 \%$ ampicillin [Sigma-Aldrich, St. Louis, MO] $)$, and a single germinated conidium was removed after $24 \mathrm{~h}$ at room temperature, and transferred to clarified V8 medium agar (Secor and Rivera 2012). Cultures were maintained on clarified V8 medium agar at room temperature for 7 to 14 days. Ten millimeter diameter agar plugs were then removed, dried overnight in a laminar flow cabinet, and kept at $-20^{\circ} \mathrm{C}$ for long-term storage.

DNA extraction. A subsample of isolates from each field was chosen randomly for genotyping. Fungal mycelia was harvested from 14-day-old cultures grown in clarified V8 broth (Jeffers 2015) at $25^{\circ} \mathrm{C}$. Fifteen to $30 \mathrm{mg}$ of lyophilized mycelium was used for extraction of genomic DNA according to the method described by Vaghefi et al. (2016). The resultant DNA was quantified using a fluorometer (Qubit 2.0; Invitrogen, Inc., Grand Island, NY) for 2014 and 2015 isolates or a Nanodrop spectrophotometer (Thermo Fisher Scientific, Waltham, MA) for 2016 isolates. Each DNA sample was examined for integrity after electrophoresis on a $1 \%(\mathrm{w} / \mathrm{v})$ agarose gel in Tris-acetate-EDTA containing $0.001 \%$ (v/v) GelRed (Biotium, Inc. Hayward, CA).

Mating type identification. To assess mating type ratios in each population, individual isolate mating types were identified using the three and four primer PCR assays described by Vaghefi et al. $(2017 \mathrm{c})$. PCR products were visualized after electrophoresis on a $2 \%$ $(\mathrm{w} / \mathrm{v})$ agarose gel in Tris-acetate-EDTA containing $0.001 \%(\mathrm{v} / \mathrm{v})$ GelRed (Biotium, Inc., Hayward, CA). Product size was determined against a 100-bp DNA Ladder (Axygen, Inc., Union City, CA).

Genotyping. Genotyping was performed for each $C$. beticola isolate using 12 microsatellite markers (CbSSR1, CbSSR2, CbSSR3, CbSSR6, CbSSR20, CbSSR21, CbSSR22, CbSSR23, CbSSR24, CbSSR25, CbSSR26, and CbSSR27) as described previously (Groenewald et al. 2007; Vaghefi et al. 2017b). Alleles were scored using the Microsatellite Plugin v. 1.4.4 in Geneious v. 10.2.3 (https://www.geneious.com, Kearse et al. 2012). To evaluate error, genotyping was replicated for $15 \%$ of the samples and error rates, defined as the number of allelic mismatches divided by the number of replicated alleles, were quantified for each locus.

Statistics and data analysis. Microsatellite dataset refinement. Multilocus genotypes (MLGs) for all isolates were determined in the $\mathrm{R}$ (R Core Team 2017) package poppr v. 2.4.1 (Kamvar et al. 2014, 2015) and the occurrence of MLGs at each location and year was assessed. In order to reduce the effect of genotyping error and missing data on genetic diversity, the data set was filtered in poppr using Bruvo's distance (Bruvo et al. 2004) in the farthest neighbor algorithm, with the filtering threshold estimated by the function cutoff_predictor (0.02083333). All subsequent analyses were conducted 
on the filtered dataset. Clone-corrected datasets were used in analyses as indicated. Population data were clone-corrected to the Location:Year level, i.e., identical MLGs from a particular location in a single year were identified and only one representative isolate from each population was retained for analyses.

Measures of genetic diversity. The number of MLGs, expected number of MLGs after rarefaction, evenness, and Nei's gene diversity (Nei 1978) were estimated in poppr. Simpson's complement index of genotypic diversity (Simpson 1949) in poppr was used to calculate the probability that two randomly selected genotypes were different, and corrected for sample size by multiplying by $\mathrm{N} /(\mathrm{N}-1)$. The number of private alleles were estimated in GenAlEx (Peakall and Smouse 2006, 2012). Allelic richness and private allelic richness were estimated with rarefaction in ADZE v. 1.0 (Szpiech et al. 2008). MLG frequencies across populations were obtained using poppr. The homogeneity of allele frequencies between years in clone-corrected datasets was assessed at each locus through construction of two way contingency tables and $\chi^{2}$ tests in POPGENE (Yeh et al. 1997).

Tests of mating type ratios and linkage equilibrium. A $\chi^{2}$ goodnessof-fit test (Mangiafico 2015) was applied to mating type frequencies to test the significance of deviations from a 1:1 ratio for both clonecorrected and non-clone-corrected population datasets. Chi-square $\left(\chi^{2}\right)$ assessments were not performed when mating type sample sizes were less than five (Farm 1 in 2015, and Farms 1 and 2 in 2016 after clone correction).

Multilocus linkage equilibrium was assessed using the index of association (Brown et al. 1980) and standardized index of association (Agapow and Burt 2001), which were estimated after 1,000 permutations in poppr, for both clone-corrected and non-clone-corrected datasets of each population.

Detection of recombination. The proportion of compatible pairs of loci (PrCP) (Estabrook and Landrum 1975) for each population was estimated using MultiLocus (Agapow and Burt 2001). Two loci are considered compatible ( $\mathrm{PrCP}=1)$ if all observed genotypes can be accounted for by mutations only in the absence of homoplasy (reversals, parallelisms, or convergences) or recombination. Under the assumption that recurrent, parallel, and reverse mutations are rare, phylogenetic incompatibility $(\mathrm{PrCP}<1)$ provides evidence of genetic exchange, and may be interpreted as evidence for recombination (Milgroom 2015). The PrCP values were assessed for statistical significance by comparing the number of compatible pairs of loci in the observed data set to those from a randomly recombined data set in MultiLocus. The null hypothesis of random mating was rejected if more compatible loci than expected in a randomized population were observed $(P<0.05)$ (Bennett et al. 2005; Xu et al. 2009).

Population structure and differentiation. Analysis of molecular variance (AMOVA) was performed on non-clone-corrected and clone-corrected datasets in GenAlEx (Peakall and Smouse 2006, 2012) to examine the genetic diversity among the six populations $\left(\Phi_{\mathrm{PT}}\right)$, with significance tested using 999 permutations. Genotypic diversities were assessed for significant differences between sampling years in GenoDive (Meirmans and Van Tienderen 2004) using 999 bootstrap replicates.

The relationships between populations were assessed using a dendrogram based on Nei's genetic distance calculated using the unweighted pair group method with arithmetic mean (UPGMA) method in poppr. Discriminant analysis of principal components (DAPC) (Jombart et al. 2010) among the six a priori clone-corrected populations was conducted in the $\mathrm{R}$ package adegenet v.2.0.1 (Jombart 2008).

Analyses of population differentiation between years were performed on a priori populations (defined as individuals from the same location:year) using both non-clone-corrected and clone-corrected datasets. Pairwise $\Phi_{\mathrm{PT}}$ (Excoffier et al. 2005), an analog of $F_{\mathrm{ST}}$

Table 1. Metadata associated with the origin of Cercospora beticola populations sampled from table beet in New York

\begin{tabular}{lllllr}
\hline Location & County & Year & Production type & & Host cultivar \\
\hline Field 2 & Genesee & 2014 & Conventional broad-acre & Ruby Queen & \\
Field 2 & Genesee & 2016 & Conventional broad-acre & Ruby Queen & \\
Farm 1 & Schuyler & 2015 & Organic mixed-cropping & Detroit & 38 \\
Farm 1 & Schuyler & 2016 & Organic mixed-cropping & Detroit & 34 \\
Farm 2 & Ontario & 2015 & Organic mixed-cropping & Detroit (62)/ Touchstone Gold (52) & 43 \\
Farm 2 & Ontario & 2016 & Organic mixed-cropping & Chioggia Guardsmark (24)/ Touchstone Gold (7) & 114 \\
Total & & & & & 31 \\
\hline
\end{tabular}

${ }^{a}$ Number of isolates within each population.

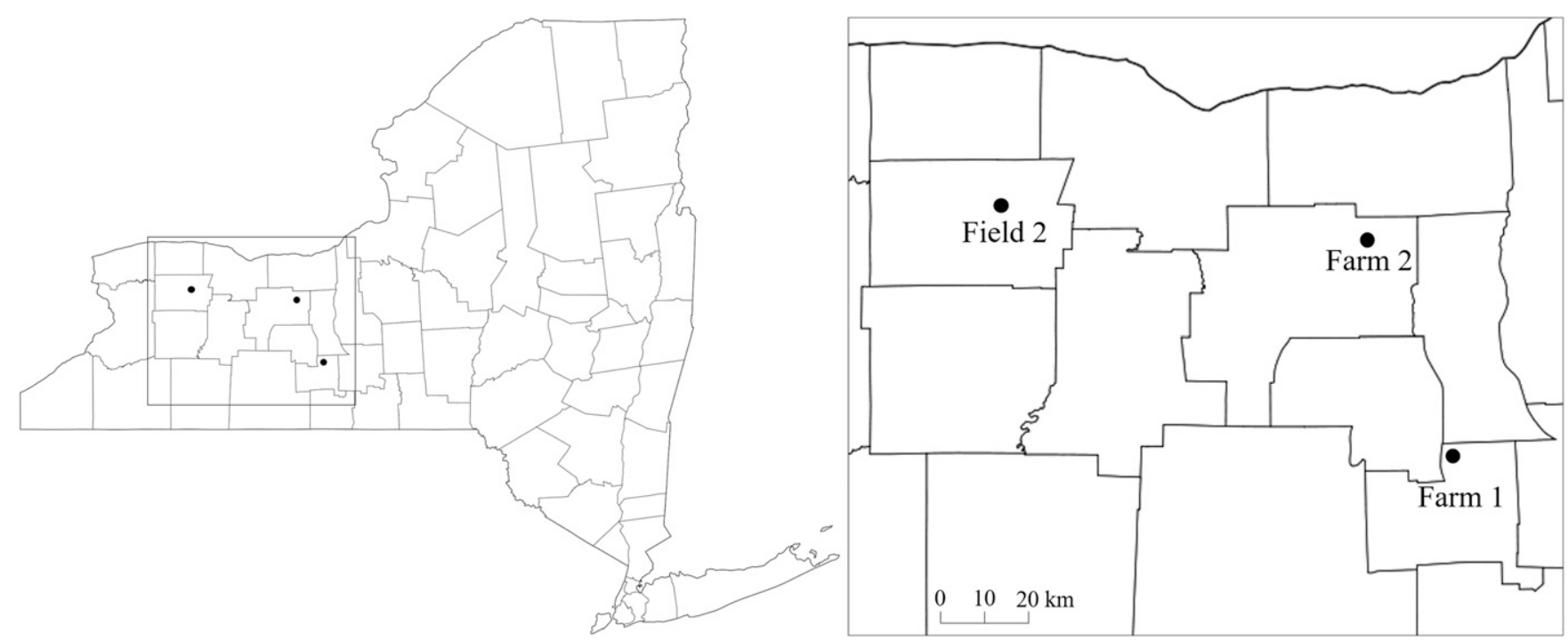

Fig. 1. Sampling locations for Cercospora beticola populations from table beet fields in New York. These images were modified in Microsoft PowerPoint 2016 from https://commons. wikimedia.org/wiki/File:Map_of_New_York_County_Outlines.svg. 
assuming a stepwise mutation model, was calculated with 999 randomizations in GenAlEx (Peakall and Smouse 2006, 2012). Jost's measure of population differentiation, where 0 and 1 indicate none and complete differentiation of populations, respectively (Jost 2008), and Hedrick's measure of genetic differentiation, (0-1; Hedrick 2005) were estimated using the package mmod (Winter 2012) in R with $95 \%$ confidence intervals estimated after 1,000 bootstrap simulations. For Hedrick's measure of genetic differentiation, the magnitude of the statistic is the proportion of the maximum differentiation possible for the level of subpopulation homozygosity observed (Hedrick 2005).

A stepwise mutation model based on Bruvo's distance (Bruvo et al. 2004) was used to calculate the genetic distance between isolates in poppr. These distances formed the basis of a minimum spanning network for both years at each location. The minimum spanning networks were viewed using the imsn() tool.

\section{Results}

C. beticola populations. Three hundred and four C. beticola isolates obtained from table beet leaves collected from two mixedcropping farms (Farms 1 and 2) in 2015 and 2016, and one broadacre table beet field (Field 2) in 2014 and 2016 (Table 1; Fig. 1) were genotyped. The genotyping error rate in the 2015 populations was 0.01 for primer pair CbSSR3. No genotyping error was detected for the 2014 and 2016 populations.

Multilocus genotypes. In the 304 C. beticola isolates, 131 unique MLGs were detected, resulting in $57 \%$ clonality of the combined populations (Table 2). Clonality varied between populations and between years for geographic origin. Field 2 populations exhibited the lowest clonality (29 and 16\% in 2014 and 2016, respectively). Populations at Farm 2 had higher levels of clonality (58 and 71\% in 2015 and 2016, respectively), while the highest clonal proportions were found in populations collected from Farm 1 (79 and 91\% in 2015 and 2016, respectively).

Indices of genetic diversity. The number of alleles across the combined $C$. beticola populations ranged from two (CbSSR2) to 28 (CbSSR3) with an average of 6.75 alleles per locus (Table 2). Nei's unbiased gene diversity $\left(\mathrm{H}_{\mathrm{e}}\right)$ per locus ranged from 0.045 (CbSSR1) to 0.89 (CbSSR3). Noninformative or monomorphic loci were present in each population (Table 2). Locus CbSSR1 was monomorphic in all populations except Farm 1 in 2015, while six loci were monomorphic at Farm 1 in 2016.
Genotypic diversity, described by Simpson's complement index, ranged from 0.178 to 0.990 (Table 2). Field 2 in both years and Farm 2 in 2015 had genotypic diversity values greater than 0.9. No MLG was shared between populations. There was a significant reduction in genotypic diversity between successive years at Farm 1 (0.496 to $0.178 ; P=0.001$ ) and Farm 2 (0.966 to $0.656 ; P=0.005$ ). A significant increase in genotypic diversity was observed in Field 2 between years $(0.978$ to $0.990 ; P=0.015)$.

Tests for random mating. Mating-type ratios. For the non-clonecorrected data set, mating-type frequencies significantly deviated from a 1:1 ratio expected under random mating for Field 2 in 2014, Farm 2 in 2016, and Farm 1 in both years (Table 3). After clone correction, mating type frequencies were significantly different from a 1:1 ratio for Field 2 in 2014.

Linkage disequilibrium of microsatellite loci. Significant linkage of microsatellite loci was detected in all populations with and without clone correction of datasets, rejecting the null hypothesis of random mating (Table 3).

Population structure. AMOVA of the combined non-clonecorrected populations found $52 \%$ of the observed genetic diversity was partitioned among the populations and $48 \%$ among individuals within populations $\left(\Phi_{\mathrm{PT}}=0.52 ; P=0.001\right)$. After clone correction, and subsequent removal of the population collected from Farm 1 in 2016 due to a small sample size $(n=4), 30 \%$ of the observed genetic diversity was partitioned among the populations and $70 \%$ among individuals within populations $\left(\Phi_{\mathrm{PT}}=0.30 ; P=0.001\right)$.

The UPGMA dendrogram, based on Nei's distance, and the DAPC analysis, using location:year as predefined populations, demonstrated that the population from Farm 2 in 2015 clustered separately from the other populations (Figs. 2 and 3).

Temporal population differentiation. The indices of differentiation quantified the genetic variation of populations between years (Table 4). Non-clone-corrected $C$. beticola populations at Field 2 $\left(\Phi_{\mathrm{PT}}=0.07 ; P=0.019\right)$ and Farm $1\left(\Phi_{\mathrm{PT}}=0.15 ; P=0.004\right)$ exhibited low but significant differentiation. In contrast, populations from Farm $2\left(\Phi_{\mathrm{PT}}=0.49 ; P=0.001\right)$ exhibited the highest level of population differentiation between years. After clone correction, Farm 2 $\left(\Phi_{\mathrm{PT}}=0.25 ; P=0.001\right)$ was the only location to exhibit significant population differentiation between years. $\chi^{2}$ tests found significant differences $(P<0.05)$ in allele frequencies between years at seven, four, and nine loci for Field 2, Farm 1, and Farm 2, respectively (Table 5; Supplementary Table S1).

Table 2. Statistics and indices of genetic diversity for Cercospora beticola populations collected from table beet fields in New York

\begin{tabular}{|c|c|c|c|c|c|c|c|c|c|c|c|c|c|c|c|c|}
\hline \multirow[b]{2}{*}{ Location } & \multirow[b]{2}{*}{ Year } & \multirow[b]{2}{*}{$\mathrm{N}^{\mathbf{a}}$} & \multirow[b]{2}{*}{$\mathbf{N a}^{\mathbf{b}}$} & \multirow[b]{2}{*}{$\mathbf{R a}^{\mathbf{c}}$} & \multirow[b]{2}{*}{$\mathbf{P a}^{\mathbf{d}}$} & \multirow[b]{2}{*}{ Prare $^{\mathrm{e}}$} & \multirow[b]{2}{*}{$\% P^{f}$} & \multirow[b]{2}{*}{ NI locig } & \multirow[b]{2}{*}{$\mathrm{He}^{\mathrm{h}}$} & \multirow[b]{2}{*}{ MLG $^{\mathbf{i}}$} & \multirow[b]{2}{*}{$\mathbf{e M L G}^{\mathbf{j}}$} & \multirow[b]{2}{*}{$\lambda^{\mathrm{k}}$} & \multirow[b]{2}{*}{$\mathbf{E 5}^{\mathbf{l}}$} & \multirow[b]{2}{*}{$\mathrm{CF}^{\mathrm{m}}$} & \multicolumn{2}{|c|}{ PrCPn } \\
\hline & & & & & & & & & & & & & & & Obs. & $P$ value \\
\hline Field 2 & 2014 & 44 & 4.33 & 1.44 & 9 & 0.36 & 91.7 & $1^{\mathrm{o}}$ & 0.436 & 31 & 23.61 & 0.978 & 0.83 & 0.29 & 0.59 & $<0.001$ \\
\hline Field 2 & 2016 & 38 & 3.83 & 1.39 & 5 & 0.25 & 91.7 & $1^{o}$ & 0.387 & 32 & 26.90 & 0.990 & 0.92 & 0.16 & 0.48 & 0.076 \\
\hline Farm 1 & 2015 & 34 & 2.50 & 1.28 & 4 & 0.24 & 91.7 & $1^{\mathrm{o}}$ & 0.278 & 7 & 6.64 & 0.496 & 0.47 & 0.79 & 1.00 & $<0.001$ \\
\hline Farm 1 & 2016 & 43 & 1.75 & 1.04 & 2 & 0.18 & 50.0 & $6^{\circ}$ & 0.045 & 4 & 3.37 & 0.178 & 0.42 & 0.91 & 1.00 & 0.331 \\
\hline Farm 2 & 2015 & 114 & 3.50 & 1.35 & 1 & 0.66 & 75.0 & $3^{\circ}$ & 0.354 & 48 & 20.92 & 0.966 & 0.70 & 0.58 & 0.48 & $<0.001$ \\
\hline Farm 2 & 2016 & 31 & 3.58 & 1.33 & 2 & 0.30 & 91.7 & $1^{o}$ & 0.335 & 9 & 9.00 & 0.656 & 0.50 & 0.71 & 0.86 & 0.002 \\
\hline Total & - & 304 & 6.75 & - & - & - & 100 & - & 0.566 & 131 & 23.25 & 0.969 & 0.43 & 0.57 & 0.11 & 0.014 \\
\hline
\end{tabular}

a Population size before clone correction.

b Mean number of alleles per locus.

c Allelic richness after rarefaction to the smallest sample size.

d Number of private alleles.

e Private allelic richness: number of private alleles after rarefaction to the smallest sample size.

f Percent polymorphic loci defined as loci with a frequency of at least 0.01 .

$\mathrm{g}$ Number of monomorphic or noninformative (minor allele frequency $<0.01$ ) loci.

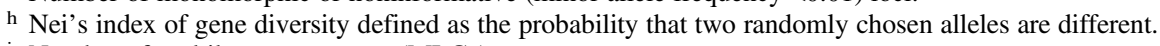

i Number of multilocus genotypes (MLGs).

j Expected number of MLGs after rarefaction.

k Simpson's complement index defined as the probability that two genotypes randomly chosen from the population are different.

${ }^{1}$ Population evenness defined as an estimation of the uniformity in distribution of the MLGs.

${ }^{\mathrm{m}}$ Clonal fraction.

${ }^{\mathrm{n}}$ Proportion of phylogenetically compatible (PrCP) pairs of loci, where Obs. denotes the observed value.

o Loci with minor allele frequency <0.01 in each population. Field 2 - 2014: CbSSR1; Field 2 - 2016: CbSSR1; Farm 1 - 2015: CbSSR24; Farm 1 - 2016: CbSSR1, CbSSR2, CbSSR22, CbSSR23, CbSSR24, and CbSSR27; Farm 2 - 2015: CbSSR1, CbSSR2 and CbSSR27; Farm 2 - 2016 : CbSSR1. 
Minimum spanning networks indicated the relationships of MLGs within and between years for each location (Fig. 4). Field 2 had MLGs from both years intermixed in the network. Farm 1, with less overall diversity, had a small genetic distance separating the two dominant MLGs (Bruvo's measure of genetic distance $=0.073$; three mutational steps, 314 to 320 bp, at CbSSR3) between years. At Farm 2 , the MLGs were most closely linked within each year.

\section{Discussion}

This study quantified temporal shifts in genetic structure of $C$. beticola populations and provided evidence of significant annual changes in genotypic diversity and allele frequencies within table beet fields in New York. Temporal population dynamics are affected by several processes, acting in combination, including selection, mutation, random genetic drift, migration, and sexual and asexual recombination (i.e., nuclear exchange, cytoplasmic exchange, or parasexuality) (Burdon 1993; Milgroom 2015; Pontecorvo 1956; Tinline and MacNeill 1969). Each of these processes has been reported or hypothesized for $C$. beticola populations (Bolton et al. 2012c; Groenewald et al. 2008; Turgay et al. 2010), and may vary in importance across environments.

C. beticola is reported to survive as pseudostromata on leaf debris, which is the primary inoculum in the subsequent season, and may persist for 10 months to 3 years in the field, depending on environmental conditions (Khan et al. 2008; Solel 1970). However, the role of survival on leaf debris in New York has not been assessed. The lack of recurring MLGs within the $C$. beticola populations sampled from the same field in subsequent years, particularly in the populations from Farm 1 containing dominant MLGs, suggests that there is limited clonal survival between years. In a temporal study on Puccinia striiformis f. sp. tritici, Ali et al. (2014) reported that limited resampling of the same MLGs over time may result from high genetic diversity or sexual recombination, and that it further suggests limited survival through clonality.

External sources of inoculum may also play a role in establishing populations, and would partly explain the observed genetic relationships of populations between years. Movement of $C$. beticola has been described on colonized host debris, seeds, and contaminated machinery, and conidia may be further dispersed locally via wind, insects, and water (McKay and Pool 1918). Alternative hosts, such as Swiss chard, may also exhibit CLS, with $C$. beticola populations not being differentiated from those of table beet (Vaghefi et al. 2017c), indicating the potential for further dispersal via alternative host plants or seed in mixed-cropping systems. The only example of significant genetic differentiation between years originated in the organic, small-scale mixed-cropping system at Farm 2, where commercial seed from two different sources was used to establish table beet crops each year. Although commercial seed was also grown at Field 2, the same

Table 3. Tests of linkage equilibrium of mating-type frequencies and microsatellite loci for Cercospora beticola populations collected from table beet fields in New York

\begin{tabular}{|c|c|c|c|c|c|c|c|c|c|c|c|}
\hline \multirow[b]{2}{*}{ Location } & \multirow[b]{2}{*}{ Year } & \multicolumn{3}{|c|}{ Non-clone-corrected } & \multicolumn{3}{|c|}{ Clone-corrected } & \multicolumn{2}{|c|}{$\begin{array}{l}\text { Non-clone- } \\
\text { corrected }\end{array}$} & \multicolumn{2}{|c|}{ Clone-corrected } \\
\hline & & MAT1-1 & MAT1-2 & $x^{2 a}$ & MAT1-1 & MAT1-2 & $x^{2}$ & $\bar{r}_{d}^{\mathbf{b}}$ & $I_{a}{ }^{\mathrm{c}}$ & $\bar{r}_{d}$ & $I_{a}$ \\
\hline Field 2 & 2014 & 36 & 8 & 17.82 & 24 & 7 & 9.32 & 0.0655 & 0.689 & 0.027 & 0.285 \\
\hline Field 2 & 2016 & 21 & 17 & 0.42 & 18 & 14 & 0.5 & 0.0631 & 0.608 & 0.0514 & 0.498 \\
\hline Farm 1 & 2015 & 7 & 27 & 11.77 & 3 & 4 & -d & 0.7062 & 6.983 & 0.4359 & 4.219 \\
\hline Farm 1 & 2016 & 2 & 41 & 35.37 & 2 & 2 & $-\mathrm{d}$ & 0.7334 & 3.482 & 0.4026 & 1.59 \\
\hline Farm 2 & 2015 & 54 & 60 & 0.32 & 20 & 28 & 1.33 & 0.0805 & 0.709 & 0.0749 & 0.696 \\
\hline Farm 2 & 2016 & 27 & 4 & 17.1 & 7 & 2 & $-\mathrm{d}$ & 0.5215 & 5.084 & 0.1286 & 1.214 \\
\hline Total & - & 147 & 157 & 0.33 & 74 & 57 & 2 & 0.2218 & 2.341 & 0.1395 & 1.473 \\
\hline
\end{tabular}

${ }^{a}$ Chi-square $\left(\chi^{2}\right)$ value based on 1:1 ratio and one degree of freedom. Mating-type frequencies with significant deviation from one $(P<0.05)$ are indicated in bold

${ }^{\mathrm{b}}$ Standardized index of association $\left(\bar{r}_{d}\right)$ scaled for the number of loci, with significant deviations from zero $(P<0.05)$ indicated in bold.

${ }^{\mathrm{c}}$ Index of association $\left(I_{a}\right)$, with significant deviations from zero $(P<0.05)$ indicated in bold.

${ }^{\mathrm{d}}$ Not applicable or not calculated due to small sample sizes.

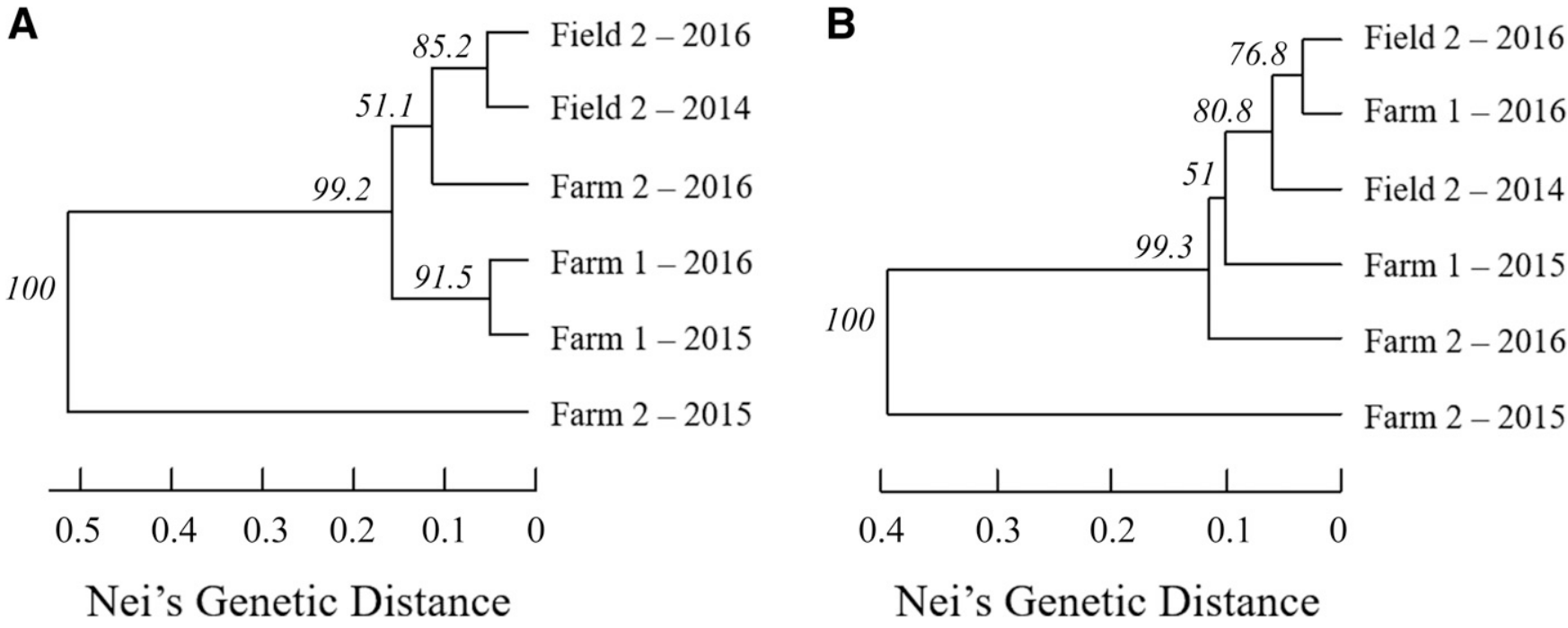

Fig. 2. Dendrogram of the relationships among $\mathbf{A}$, non-clone-corrected and $\mathbf{B}$, clone-corrected Cercospora beticola populations sampled from each of three table beet fields in successive years in New York. The dendrogram was constructed using the unweighted pair group method with arithmetic mean based on Nei's genetic distance. Numbers at branch points indicate the percent occurrence of the cluster to the right of the branch in 1,000 bootstrapped dendrograms. 
supplier was used each year. Thus, the maintenance of diversity and low differentiation between years at Field 2 would be supported by a recurring diverse founder population. This implication requires that seedborne inoculum is present on the purchased seed and has the potential to start a genetically distinct population. Evidence for seedborne inoculum, or infections originating from seed, is limited (McKay and Pool 1918; Vereijssen et al. 2004). Further examination of the potential role of seedborne inoculum in New York is required.

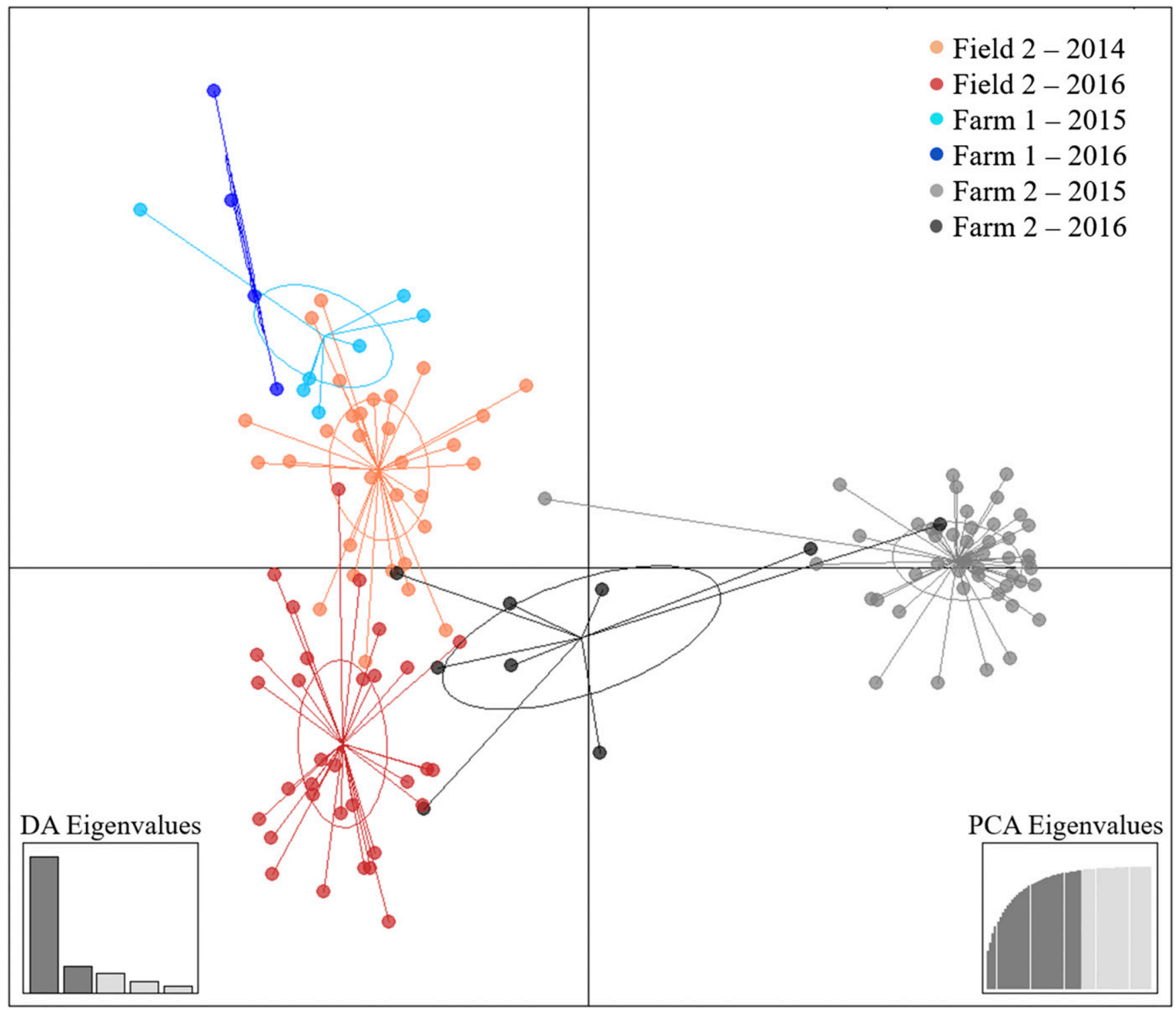

Fig. 3. Discriminant analysis of principal components for clone-corrected Cercospora beticola populations collected from table beet fields (Field 2 and Farms 1 and 2 ) in New York in 2014,2015 , and 2016. The frequency distributions of the eigenvalues (insets) of the discriminant analysis (DA) and the principal component analysis (PCA) showed that the first two principal components adequately accounted for the genetic structure of the populations.

Table 4. Indices of temporal differentiation for Cercospora beticola populations collected in each of two years from three table beet fields in New York. Probability values $(P)$ and $95 \%$ confidence intervals $(\mathrm{CI})$ were estimated after 999 randomizations.

\begin{tabular}{lllr}
\hline & \multicolumn{3}{c}{ Index of differentiation } \\
\cline { 2 - 4 } Location & $\boldsymbol{\Phi}_{\mathbf{P T}}(\boldsymbol{P}$ value $)$ & Jost's D (95\% CI) & Hedrick's G'ST (95\% CI) \\
\hline Non-clone-corrected & & & \\
$\quad$ Field 2 $(n=82)$ & $0.07(0.019)$ & $0.08(0.047$ to 0.113$)$ & $0.18(0.114$ to 0.239$)$ \\
Farm 1 $(n=77)$ & $0.15(0.004)$ & $0.09(0.069$ to 0.106$)$ & $0.37(0.323$ to 0.427$)$ \\
Farm 2 $(n=145)$ & $0.49(0.001)$ & $0.57(0.528$ to 0.614$)$ & $0.80(0.760$ to 0.832$)$ \\
Clone-corrected & & & \\
Field 2 $(n=63)$ & $0.02(0.198)$ & $0.07(0.031$ to 0.103$)$ & $0.15(0.076$ to 0.218$)$ \\
Farm 1 $(n=11)$ & $0.14(0.193)$ & $0.11(0.000$ to 0.225$)$ & $0.24(0.076$ to 0.404$)$ \\
Farm 2 $(n=57)$ & $0.25(0.001)$ & $0.30(0.201$ to 0.409$)$ & $0.47(0.353$ to 0.596$)$ \\
\hline
\end{tabular}

${ }^{a}$ Confidence interval of non-clone-corrected dataset calculated by subtracting the difference between the point estimate of the statistic and the mean of the bootstrap distribution from the extremes of the interval. Confidence interval of clone-corrected dataset utilized lower.normal and upper.normal centered on the observed value of the statistic and standard deviation across replicates to generate limits (also called the normal-method of obtaining a confidence interval: the intervals are the observed value statistic $\pm 1.96 \times$ the standard error of the bootstrap sample) (Winter et al. 2017). 
In contrast to Farm 2 and Field 2, Farm 1 established crops annually from seed produced at the same location. The low diversity, along with the more stable allele frequencies, at Farm 1 suggested a significant effect of the farm-based seed production, potentially by limiting introduction of external inoculum. Farm 1 had a unique dominant MLG in each year, and while the genetic distance between these MLGs was relatively small (three mutational steps), it does indicate a complete shift in the dominant MLG between years. The mutation producing this shift occurred at the highly polymorphic dinucleotide simple sequence repeat locus, CbSSR3 (Groenewald et al. 2007). The high frequency of polymorphisms at this locus could be impacted by an increased error rate (Vaghefi et al. 2017c); however, as no error was detected for these isolates, a high mutation rate at this locus is the most likely source of variation. While a mutation could create the genetic difference in the MLGs between years, it does not account for the absence of the dominant 2015 MLG in the subsequent year. This finding suggests that the MLG composition of the population in the previous year is unlikely to contribute to subsequent CLS epidemics, again discounting the dominance of survival through local clonal inoculum.

The role of mutation in the differentiation of populations between years may explain some of the minor genetic variation and infrequent

Table 5. Comparison of allele frequencies at 12 microsatellite loci between years for clone-corrected Cercospora beticola populations at each table beet field using a chi-squared $\left(\chi^{2}\right)$ analysis. Probability values $(P)$ were estimated after 999 randomizations

\begin{tabular}{|c|c|c|c|c|c|c|c|c|c|}
\hline \multirow[b]{2}{*}{ Locus } & \multicolumn{3}{|c|}{ Field 2} & \multicolumn{3}{|c|}{ Farm 1} & \multicolumn{3}{|c|}{ Farm 2} \\
\hline & $\chi^{2}$ & $d f^{\mathbf{a}}$ & $P$ value & $\chi^{2}$ & df & $P$ value & $x^{2}$ & df & $P$ value \\
\hline CbSSR1 & 2.10 & 1 & 0.15 & 4.71 & 1 & 0.03 & 0.00 & 0 & $1.00^{\mathrm{b}}$ \\
\hline CbSSR2 & 13.04 & 1 & $<0.001$ & 4.71 & 1 & 0.03 & 33.99 & 1 & $<0.001$ \\
\hline CbSSR3 & 94.26 & 20 & $<0.001$ & 22.00 & 9 & 0.01 & 80.16 & 10 & $<0.001$ \\
\hline CbSSR6 & 41.30 & 7 & $<0.001$ & 3.99 & 2 & 0.14 & 51.04 & 5 & $<0.001$ \\
\hline CbSSR20 & 2.69 & 2 & 0.26 & 7.18 & 3 & 0.07 & 56.28 & 3 & $<0.001$ \\
\hline CbSSR 21 & 10.38 & 4 & 0.03 & 4.71 & 2 & 0.09 & 40.05 & 5 & $<0.001$ \\
\hline CbSSR22 & 6.52 & 3 & 0.09 & 2.79 & 1 & 0.09 & 36.59 & 2 & $<0.001$ \\
\hline CbSSR23 & 2.40 & 2 & 0.30 & 2.79 & 1 & 0.09 & 20.34 & 4 & $<0.001$ \\
\hline CbSSR24 & 22.15 & 4 & $<0.001$ & 0.00 & 0 & $1.00^{\mathrm{b}}$ & 0.65 & 3 & 0.88 \\
\hline CbSSR25 & 23.96 & 4 & $<0.001$ & 10.48 & 3 & 0.01 & 52.45 & 5 & $<0.001$ \\
\hline CbSSR26 & 7.65 & 2 & 0.02 & 0.39 & 1 & 0.53 & 3.58 & 1 & 0.06 \\
\hline CbSSR27 & 4.13 & 2 & 0.13 & 2.79 & 1 & 0.09 & 46.02 & 1 & $<0.001$ \\
\hline
\end{tabular}

${ }^{\mathrm{a}} \mathrm{df}=$ degrees of freedom

${ }^{\mathrm{b}}$ Monomorphic loci in both years.
MLGs; however, mutation is unlikely to explain all of the genetic diversity observed in C. beticola populations (Bolton et al. 2012c). Mutation rates of microsatellites vary between species, but are generally appreciable $\left(10^{-3}\right.$ to $10^{-6}$ per generation $)$ and have been suggested to be an important factor in the creation and maintenance of genetic variation (Ellegren 2000; Karaoglu et al. 2004; Schug et al. 1997; Weber and Wong 1993; Xu et al. 2000). Few studies of mutation rates in fungal plant pathogens are available (Karaoglu et al. 2004), but the multiple generations of $C$. beticola produced during polycyclic CLS epidemics provides a conducive system for the occurrence of mutations in microsatellite regions.

A study of the pathogen Sclerotinia sclerotiorum demonstrated that with a sublethal fungicide selection pressure, estimated mutation rates in six microsatellite markers were 1.7 - to 60 -fold higher than expected under neutral conditions (Amaradasa and Everhart 2016). Field 2 was maintained using conventional practices (fungicidetreated seed, in-furrow fungicide applications for pocket rot control, and two to three foliar fungicides applications [Reiners et al. 2017]) and it may be expected that a subset of the field population would be exposed to sublethal fungicide levels. Therefore, mutation due to exposure with a sublethal fungicide selection pressure, in a population with high diversity, may allow for the consistently high allelic and genotypic diversity in populations surviving as local inoculum. Alternatively, high genotypic diversity may also be consistent with an active sexual morph.

Indications of sexual recombination have been described for C. beticola populations based on the presence of both mating types in equilibrium, high genotypic diversity, and gametic equilibrium, but no teleomorph has been identified (Groenewald et al. 2008; Vaghefi et al. 2016, 2017a, c). Each population in this study contained both mating types but only two of the six populations exhibited equilibrium, which is an indication of random mating (Milgroom 1996). For example, equilibrium was detected at Farm 2 in 2015 but not in the subsequent year, reflecting the differentiation of populations. However, at Field 2, the 2016 population moved into mating type equilibrium. A change in allele frequencies, including mating types, may be the result of genetic drift caused by bottleneck effects or selection events in the founder population (Chen et al. 1994). The disequilibrium of microsatellite loci has been similarly described by Vaghefi et al. (2017c), with the significant disequilibrium not being of suggestive of random mating (Milgroom 1996). These results, however, are not conclusive evidence of the lack of sexual recombination (Vaghefi et al. 2017c). Studies of New York C. beticola populations have suggested the presence of a mixed mode of reproduction
A

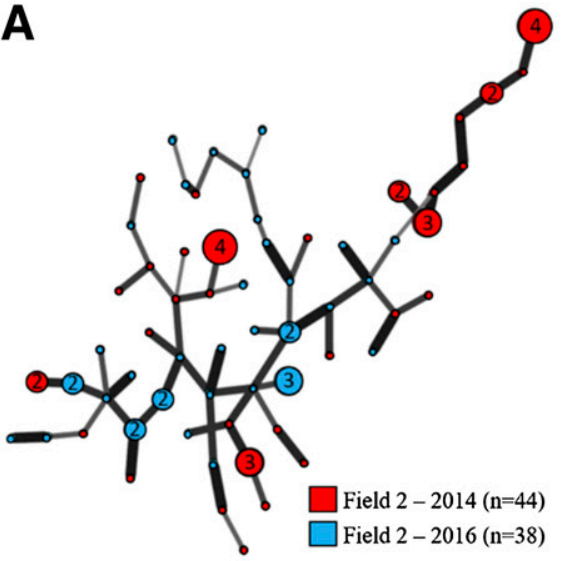

B

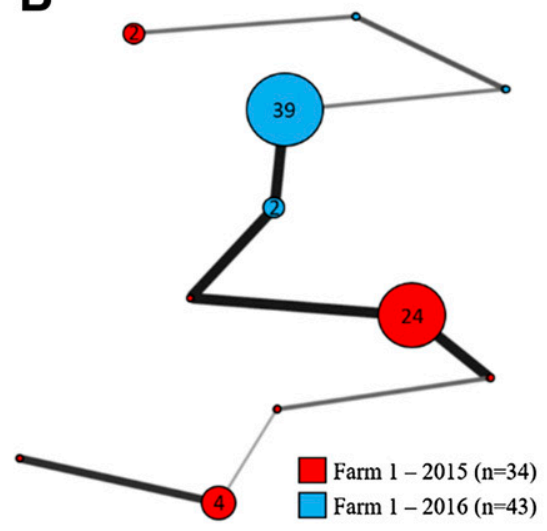

C

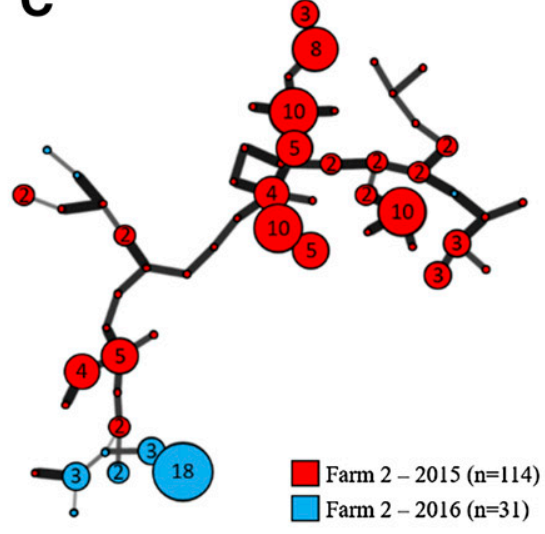

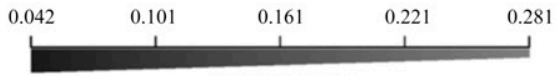

DISTANCE

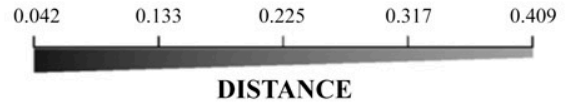

DISTANCE

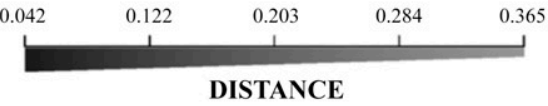

DISTANCE

Fig. 4. Minimum spanning networks for Cercospora beticola multilocus genotypes (MLGs) based on Bruvo's measure of genetic distance from A, Field 2 in 2014 and 2016 , B, Farm 1 in 2015 and 2016, and C, Farm 2 in 2015 and 2016. Each node represents an MLG and node sizes are proportional to the frequency of the MLGs. Edge width and color are proportional to the genetic distance between MLGs. 
(Vaghefi et al. 2016), with potential for infrequent recombination events.

Assessment of clonality was performed by testing the presence of phylogenetic incompatibility between pairs of loci. This test has an assumption that recurrent, parallel, and reverse mutations are highly improbable and phylogenetic incompatibility of loci may only arise by recombination (Milgroom 2015). Fourteen to $52 \%$ of pairs of loci were incompatible for Field 2 and Farm 2 in both years, while no pairs of loci were incompatible at Farm 1 in both years. This suggests recombination may have occurred in the Field 2 and Farm 2 populations. The high diversity at Field 2 also suggests recombination. Populations at Farm 2 possessed some features reflective of recombination, but the significant differentiation and change in proportion of phylogenetically compatible pairs suggests a dominant role of external inoculum. Vaghefi et al. (2017c) suggested that epidemics in mixed-cropping farms may originate from local inoculum sources but a role for infested seed as an inoculum source was also identified. Based on similarities of populations between broad-acre fields, Vaghefi et al. (2017c) also suggested that external inoculum sources are contributing to CLS epidemics in these fields. The lack of differentiation at Field 2 supports the role of a recurrent external inoculum source, or founder population, at this location. Further investigation of temporal changes in diversity of $C$. beticola populations, coinciding with more intensive sampling, assessment of potential inoculum sources, and surveys for sexual stages, are therefore essential.

A significant factor for consideration during temporal comparisons is the effect of sampling strategy. In a highly diverse population, intensive sampling is required to identify the same low frequency MLG between sampling times. Therefore, a lack of recurring MLGs between years would be possible due to sampling effects, such as in Field 2. However, in a less diverse population, such as Farm 1, it would be more likely that a high frequency MLG would be resampled. As no MLG was resampled between years at any location, the roles of recombination, selection, genetic drift, and inoculum sources must be examined.

The differentiation, nonrecurrent MLGs, and changes in genotypic diversity and allele frequency observed in this study demonstrate potential for annual genetic change in C. beticola populations. This has important implications for disease management strategies, particularly an increased risk of fungicide resistance development. A high frequency of $C$. beticola isolates resistant to azoxystrobin have been reported in New York (Abawi et al. 2014). High diversity and rapid genetic change coinciding with the application of fungicides increases the potential for a shift in the frequency of resistance genes, which highlights the need to adhere to best management guidelines for fungicides in conventional table beet production.

To improve our knowledge on the role of primary inoculum in CLS epidemics, further mechanistic research is required. As the three locations in this study exhibited distinctly different temporal relationships, the potential for genetic shifts in C. beticola populations between seasons also needs to be accommodated in future studies.

\section{Acknowledgments}

We thank Carol Bowden, Traci Hoogland, Elizabeth Maloney, and David Strickland for assistance with sample collection and excellent technical support. We are also grateful to the growers involved in this study for access to their fields for collection of diseased specimens.

\section{Literature Cited}

Abawi, G. S., Kikkert, J. R., Moktan, K., Lange, H. W., and Smart, C. D. 2014. First report of resistance to Quadris among populations of Cercospora beticola causing leaf spot of table beet in New York State. Phytopathology 104:S1.1.

Agapow, P.-M., and Burt, A. 2001. Indices of multilocus linkage disequilibrium. Mol. Ecol. Notes 1:101-102.

Ali, S., Gladieux, P., Rahman, H., Saqib, M. S., Fiaz, M., Ahmad, H., Leconte, M., Gautier, A., Justesen, A. F., Hovmøller, M. S., Enjalbert, J., and de VallavieillePope, C. 2014. Inferring the contribution of sexual reproduction, migration and off-season survival to the temporal maintenance of microbial populations: a case study on the wheat fungal pathogen Puccinia striiformis f.sp. tritici. Mol. Ecol. 23:603-617.
Amaradasa, B. S., and Everhart, S. E. 2016. Effects of sublethal fungicides on mutation rates and genomic variation in fungal plant pathogen, Sclerotinia sclerotiorum. PLoS One 11:e0168079.

Bakhshi, M., Arzanlou, M., and Babai-Ahari, A. 2011. Uneven distribution of mating type alleles in Iranian populations of Cercospora beticola, the causal agent of Cercospora leaf spot disease of sugar beet. Phytopathol. Mediterr. 50:101-109.

Bennett, R. S., Milgroom, M. G., and Bergstrom, G. C. 2005. Population structure of seedborne Phaeosphaeria nodorum on New York wheat. Phytopathology 95:300-305.

Bolton, M. D., Birla, K., Rivera-Varas, V., Rudolph, K. D., and Secor, G. A. 2012a. Characterization of CbCyp51 from field isolates of Cercospora beticola. Phytopathology 102:298-305.

Bolton, M. D., Rivera-Varas, V., del Río Mendoza, L. E., Khan, M. F. R., and Secor, G. A. 2012b. Efficacy of variable tetraconazole rates against Cercospora beticola isolates with differing in vitro sensitivities to DMI fungicides. Plant Dis. 96:1749-1756.

Bolton, M. D., Secor, G. A., Rivera, V., Weiland, J. J., Rudolph, K., Birla, K., Rengifo, J., and Campbell, L. G. 2012c. Evaluation of the potential for sexual reproduction in field populations of Cercospora beticola from USA. Fungal Biol. 116:511-521.

Brown, A. H. D., Feldman, M. W., and Nevo, E. 1980. Multilocus structure of natural populations of Hordeum spontaneum. Genetics 96:523-536.

Bruvo, R., Michiels, N. K., D'Souza, T. G., and Schulenburg, H. 2004. A simple method for the calculation of microsatellite genotype distances irrespective of ploidy level. Mol. Ecol. 13:2101-2106.

Bugbee, W. 1996. Cercospora beticola strains from sugar beet tolerant to triphenyltin hydroxide and resistant to thiophanate methyl. Plant Dis. 80:103.

Burdon, J. 1993. The structure of pathogen populations in natural plant communities. Annu. Rev. Phytopathol. 31:305-323.

Burdon, J. J., and Silk, J. 1997. Sources and patterns of diversity in plantpathogenic fungi. Phytopathology 87:664-669.

Chen, R. S., Boeger, J. M., and McDonald, B. A. 1994. Genetic stability in a population of a plant pathogenic fungus over time. Mol. Ecol. 3:209-218.

Dovas, C., Skylakakis, G., and Georgopoulos, S. 1976. The adaptability of the benomyl-resistant population of Cercospora beticola in northern Greece. Phytopathology 66:1452-1456.

Ellegren, H. 2000. Microsatellite mutations in the germline: implications for evolutionary inference. Trends Genet. 16:551-558.

Estabrook, G., and Landrum, L. 1975. A simple test for the possible simultaneous evolutionary divergence of two amino acid positions. Taxon 24:609-613.

Excoffier, L., Laval, G., and Schneider, S. 2005. Arlequin (version 3.0): An integrated software package for population genetics data analysis. Evol. Bioinform. Online 1:47-50.

Franc, G. D. 2010. Ecology and epidemiology of Cercospora beticola. Pages 7-19 in: Cercospora leaf spot of sugar beet and related species. R. T. Lartey, J. J. Weiland, L. Panella, P. W. Crous, and C. E. Windels, eds. The American Phytopathological Society, St. Paul, MN.

Georgopoulos, S., and Dovas, C. 1973. A serious outbreak of strains of Cercospora beticola resistant to benzimidazole fungicides in Northern Greece. Plant Dis. Rep. 57:321-324.

Giannopolitis, C. 1978. Occurrence of strains of Cercospora beticola resistant to triphenyltin fungicides in Greece. Plant Dis. Rep. 62:205-208.

Giannopolitis, C., and Chrysayi-Tokousbalides, M. 1980. Biology of triphenyltinresistant strains of Cercospora beticola from sugar beet. Plant Dis. 64:940-942.

Groenewald, M., Groenewald, J. Z., Harrington, T. C., Abeln, E. C., and Crous, P. W. 2006. Mating type gene analysis in apparently asexual Cercospora species is suggestive of cryptic sex. Fungal Genet. Biol. 43:813-825.

Groenewald, M., Groenewald, J. Z., Linde, C. C., and Crous, P. W. 2007. Development of polymorphic microsatellite and single nucleotide polymorphism markers for Cercospora beticola (Mycosphaerellaceae). Mol. Ecol. Notes 7 : 890-892.

Groenewald, M., Linde, C. C., Groenewald, J. Z., and Crous, P. W. 2008. Indirect evidence for sexual reproduction in Cercospora beticola populations from sugar beet. Plant Pathol. 57:25-32.

Hedrick, P. W. 2005. A standardized genetic differentiation measure. Evolution 59:1633-1638.

Jacobsen, B. J., and Franc, G. D. 2009. Cercospora leaf spot. Pages 7-10 in: Compendium of Beet Diseases and Pests. R. M. Harveson, L. E. Hanson, and G. L. Hein, eds. American Phytopathological Society, St. Paul, MN.

Jeffers, S. 2015. PROTOCOL 07-11.1: V8 agar (V8A) or broth. Pages 1-2 in: Laboratory Protocols for Phytophthora Species. J. Steve, ed. The American Phytopathological Society, St. Paul, MN

Jombart, T. 2008. adegenet: a R package for the multivariate analysis of genetic markers. Bioinformatics 24:1403-1405.

Jombart, T., Devillard, S., and Balloux, F. 2010. Discriminant analysis of principal components: a new method for the analysis of genetically structured populations. BMC Genet. 11:94.

Jost, L. O. U. 2008. $\mathrm{G}_{\mathrm{ST}}$ and its relatives do not measure differentiation. Mol. Ecol 17:4015-4026.

Kamvar, Z. N., Brooks, J. C., and Grünwald, N. J. 2015. Novel R tools for analysis of genome-wide population genetic data with emphasis on clonality. Front Genet. 6:208. 
Kamvar, Z. N., Tabima, J. F., and Grünwald, N. J. 2014. Poppr: an R package for genetic analysis of populations with clonal, partially clonal, and/or sexual reproduction. PeerJ 2:e281.

Karaoglanidis, G. S., Ioannidis, P. M., and Thanassoulopoulos, C. C. 2000. Reduced sensitivity of Cercospora beticola isolates to sterol-demethylationinhibiting fungicides. Plant Pathol. 49:567-572.

Karaoglanidis, G. S., Loannidis, P. M., and Thanassoulopoulos, C. C. 2002. Changes in sensitivity of Cercospora beticola populations to steroldemethylation-inhibiting fungicides during a 4-year period in northern Greece. Plant Pathol. 51:55-62.

Karaoglanidis, G. S., Thanassoulopoulos, C. C., and Ioannidis, P. M. 2001. Fitness of Cercospora beticola field isolates - resistant and - sensitive to demethylation inhibitor fungicides. Eur. J. Plant Pathol. 107:337-347.

Karaoglu, H., Lee, C. M. Y., and Meyer, W. 2004. Survey of simple sequence repeats in completed fungal genomes. Mol. Biol. Evol. 22:639-649.

Kearse, M., Moir, R., Wilson, A., Stones-Havas, S., Cheung, M., Sturrock, S., Buxton, S., Cooper, A., Markowitz, S., Duran, C., Thierer, T., Ashton, B., Meintjes, P., and Drummond, A. 2012. Geneious Basic: An integrated and extendable desktop software platform for the organization and analysis of sequence data. Bioinformatics 28:1647-1649.

Khan, J., Rio, L. E., Nelson, R., Rivera-Varas, V., Secor, G. A., and Khan, M. F. R. 2008. Survival, dispersal, and primary infection site for Cercospora beticola in sugar beet. Plant Dis. 92:741-745.

Koenick, L., Kikkert, J. R., and Pethybridge, S. J. 2017. Cercospora leaf spot of table beet. http://vegetablemdonline.ppath.cornell.edu/factsheets/CLS-Extension-BulletinRevised-2017_final-tbrddk.pdf. Accessed: 13 October 2017.

Lartey, R., Caesar-TonThat, T., Caesar, A., Shelver, W., Sol, N., and Bergman, J. 2005. Safflower: a new host of Cercospora beticola. Plant Dis. 89:797-801.

Lartey, R. T., Weiland, J. J., Panella, L., Crous, P. W., and Windels, C. E. 2010. Cercospora leaf spot of sugar beet and related species. APS Press, St. Paul, MN.

Mangiafico, S. S. 2015. An R companion for the handbook of biological statistics, version 1.09 i. Rutgers Cooperative Extension, New Brunswick.

McGrath, J. M., Saccomani, M., Stevanato, P., and Biancardi, E. 2007. Beet. Pages 191-207 in: Genome Mapping and Molecular Breeding in Plants, vol. 5: Vegetables. C. Kole, ed. Springer, Berlin.

McKay, M. B., and Pool, V. W. 1918. Field studies of Cercospora beticola. Phytopathology 8:119-136.

Meirmans, P. G., and Van Tienderen, P. H. 2004. GENOTYPE and GENODIVE: two programs for the analysis of genetic diversity of asexual organisms. Mol. Ecol. Notes 4:792-794.

Milgroom, M. G. 1996. Recombination and the multilocus structure of fungal populations. Annu. Rev. Phytopathol. 34:457-477.

Milgroom, M. G. 2015. Population biology of plant pathogens: Genetics, ecology, and evolution. APS Press, St. Paul, MN.

Moretti, M., Karaoglanidis, G., Saracchi, M., Fontana, A., and Farina, G. 2006. Analysis of genotypic diversity in Cercospora beticola Sacc. field isolates. Ann. Microbiol. 56:215-221.

Moretti, M., Saracchi, M., and Farina, G. 2004. Morphological, physiological and genetic diversity within a small population of Cercospora beticola Sacc. Ann. Microbiol. 54:129-150.

Nei, M. 1978. Estimation of average heterozygosity and genetic distance from a small number of individuals. Genetics 89:583-590.

Obuya, J., Hanson, L., and Franc, G. 2011. Mating type idiomorphs distribution and their correlation to benzimidazole-resistance in Cercospora beticola from the Central High Plains region, USA. Pages 10-114 in: American Society of Sugar Beet Technologists, Proceedings from the 36th Biennial Meeting, March 2-5, 2011, Albuquerque, New Mexico, USA, American Society of Sugar Beet Technologists.

Peakall, R., and Smouse, P. E. 2012. GenAlEx 6.5: genetic analysis in Excel. Population genetic software for teaching and research-an update. Bioinformatics 28:2537-2539.

Peakall, R. O. D., and Smouse, P. E. 2006. GENALEX 6: genetic analysis in Excel. Population genetic software for teaching and research. Mol. Ecol. Notes 6: 288-295.

Pethybridge, S. J., Vaghefi, N., and Kikkert, J. R. 2017a. Horticultural characteristics and susceptibility of table beet cultivars to Cercospora leaf spot in New York. HortTechnology 27:530-538.

Pethybridge, S. J., Vaghefi, N., and Kikkert, J. R. 2017b. Management of Cercospora leaf spot in conventional and organic table beet production. Plant Dis. 101:1642-1651.

Pontecorvo, G. 1956. The parasexual cycle in fungi. Annu. Rev. Microbiol. 10: $393-400$.
Pool, V. W., and McKay, M. 1916. Climatic conditions as related to Cercospora beticola. J. Agric. Res. 6:21-60.

R Core Team. 2017. R: A language and environment for statistical computing. R Foundation for Statistical Computing, Vienna, Austria.

Reiners, S., Bellinder, R. R., Curtis, P. D., Helms, M., Landers, A. J., McGrath, M T., Nault, B. A., and Seaman, A. 2017. Beets. Pages 114-121 in: Cornell integrated crop and pest management guidelines for commercial vegetable production. Cornell Cooperative Extension, Ithaca, NY.

Ruppel, E., and Scott, P. 1974. Strains of Cercospora beticola resistant to benomyl in the USA. Plant Dis. Rep. 58:434-436.

Schug, M. D., Mackay, T. F. C., and Aquadro, C. F. 1997. Low mutation rates of microsatellite loci in Drosophila melanogaster. Nat. Genet. 15:99-102.

Secor, G. A., and Rivera, V. V. 2012. Fungicide resistance assays for fungal plant pathogens. Pages 385-392 in: Plant Fungal Pathogens: Methods and Protocols. M. D. Bolton and B. P. H. J. Thomma, eds. Humana Press, Totowa, NJ.

Shane, W. W., and Teng, P. S. 1992. Impact of Cercospora leaf spot on root weight, sugar yield, and purity of Beta vulgaris. Plant Dis. 76:812-820.

Simpson, E. H. 1949. Measurement of diversity. Nature 163:688.

Smith, G., and Martin, S. 1978. Differential response of sugarbeet cultivars to Cercospora leaf spot disease. Crop Sci. 18:39-42.

Smith, G., and Ruppel, E. 1973. Association of Cercospora leaf spot, gross sucrose, percentage sucrose, and root weight in sugarbeet. Can. J. Plant Sci. 53:695-696.

Solel, Z. 1970. Survival of Cercospora beticola, the causal agent of sugar beet leaf spot, in Israel. Trans. Br. Mycol. Soc. 54:504-506.

Szpiech, Z. A., Jakobsson, M., and Rosenberg, N. A. 2008. ADZE: a rarefaction approach for counting alleles private to combinations of populations. Bioinformatics 24:2498-2504.

Tinline, R., and MacNeill, B. 1969. Parasexuality in plant pathogenic fungi. Annu. Rev. Phytopathol. 7:147-168

Turgay, E. B., Bakir, M., Ozeren, P., Katircioglu, Y. Z., and Maden, S. 2010 Detection of pathotypes and genetic diversity of Cercospora beticola. Plant Pathol. J. 26:306-312.

USDA. 2012. USDA-NASS Quick Stats. https://www.nass.usda.gov/Quick_Stats/. Accessed 17 August 2017.

Vaghefi, N., Hay, F. S., Kikkert, J. R., and Pethybridge, S. J. 2016. Genotypic diversity and resistance to azoxystrobin of Cercospora beticola on processing table beet in New York. Plant Dis. 100:1466-1473.

Vaghefi, N., Kikkert, J. R., Bolton, M. D., Hanson, L. E., Secor, G. A., Nelson, S. C., and Pethybridge, S. J. 2017a. Global genotype flow in Cercospora beticola populations confirmed through genotyping-by-sequencing. PLoS One 12:e0186488

Vaghefi, N., Kikkert, J. R., Bolton, M. D., Hanson, L. E., Secor, G. A., and Pethybridge, S. J. 2017b. De novo genome assembly of Cercospora beticola for microsatellite marker development and validation. Fungal Ecol. 26:125-134

Vaghefi, N., Nelson, S. C., Kikkert, J. R., and Pethybridge, S. J. 2017c. Genetic structure of Cercospora beticola populations on Beta vulgaris in New York and Hawaii. Sci. Rep. 7:1726.

Vereijssen, J., Schneider, H. J. H. M., and Termorshuizen, A. A. J. 2004. Possible root infection of Cercospora beticola in sugar beet. Eur. J. Plant Pathol. 110: 103-106.

Vestal, E. F. 1933. Pathogenicity, host response and control of Cercospora leafspot of sugar beets. Res. Bull. (Int. Comm. Northwest Atl. Fish.) 14:1 (Iowa Agriculture and Home Economics Experiment Station).

Weber, J. L., and Wong, C. 1993. Mutation of human short tandem repeats. Hum. Mol. Genet. 2:1123-1128.

Weiland, J., Eide, J., Rivera-Varas, V., and Secor, G. 2001. Genetic diversity of Cercospora beticola in the US and association of molecular markers with tolerance to the fungicide triphentylin hydroxide. Phytopathology 91:S94.

Weiland, J. J., and Halloin, J. M. 2001. Benzimidazole resistance in Cercospora beticola sampled from sugarbeet fields in Michigan, U.S.A. Can. J. Plant Pathol. 23:78-82.

Winter, D., Green, P., Kamvar, Z., and Gosselin, T. 2017. Package 'mmod'. Genetics 47:253-259.

Winter, D. J. 2012. MMOD: an R library for the calculation of population differentiation statistics. Mol. Ecol. Resour. 12:1158-1160

$\mathrm{Xu}$, J., Yan, Z., and Guo, H. 2009. Divergence, hybridization, and recombination in the mitochondrial genome of the human pathogenic yeast Cryptococcus gattii. Mol. Ecol. 18:2628-2642.

$\mathrm{Xu}$, X., Peng, M., Fang, Z., and Xu, X. 2000. The direction of microsatellite mutations is dependent upon allele length. Nat. Genet. 24:396-399.

Yeh, F. C., Yang, R., Boyle, T., Ye, Z., and Mao, J. X. 1997. POPGENE, the user friendly shareware for population genetic analysis. Molecular Biology and Biotechnology Centre, University of Alberta, Canada. 